\title{
Copper and Manganese Cations Alter Secondary Metabolism in the Fungus Penicillium brasilianum
}

\author{
Taícia Pacheco Fill, ${ }^{*, a}$ Heloisa Fassina Pallini, ${ }^{b}$ Luciana da Silva Amaral, ${ }^{b}$ \\ José Vinicius da Silva, ${ }^{b}$ Danielle Lazarin Bidóia, ${ }^{c}$ Francieli Peron, ${ }^{c}$ Francielle Pelegrin \\ Garcia, ${ }^{c}$ Celso Vataru Nakamura ${ }^{c}$ and Edson Rodrigues-Filho ${ }^{b}$
}

\author{
anstituto de Química, Universidade Estadual de Campinas, CP 6154, 13083-970 Campinas-SP, Brasil \\ ${ }^{b}$ Departamento de Química, Universidade Federal de São Carlos, CP 676, 13565-905 São Carlos-SP, Brazil \\ ${ }^{c}$ Laboratório de Inovação Tecnológica no Desenvolvimento de Fármacos e Cosméticos, \\ Universidade Estadual de Maringá, Av. Colombo 5790, Bloco B-08, 87020-900 Maringá-PR, Brazil
}

\begin{abstract}
The fungus Penicillium brasilianum LaBioMMi 136 was isolated as an endophyte from Melia azedarach and has shown to be a prominent producer of great diversity of secondary metabolites, although it does not express some biosynthetic routes to other natural compounds found in Penicillium genera. The present study aimed at the diversification of $P$. brasilianum secondary metabolism by varying the chemical composition used for its growth. Medium composition supplemented with $\mathrm{CuSO}_{4}$ and $\mathrm{MnSO}_{4}$ locked verruculogen biosynthesis and addressed proline to the production of a series of cyclodepsipeptides identified as JBIR 113, JBIR 114 and JBIR 115, never described for this species so far. The induced cyclodepsipeptide JBIR 113 was isolated by the use of combined chromatographic procedures and identified by spectroscopic methods. The unique structure with three neighboring cyclic amino acids proline and twice pipecolinic acid is rare as natural products and has been described for the first time in terrestrial organism. Verruculogen and JBIR 113 exhibited weak antiparasitary activity against Leishmania amazonensis.
\end{abstract}

Keywords: cyclodepsipeptide, verruculogen, Penicillium brasilianum, JBIR 113

\section{Introduction}

Microbial natural products continue to represent an important source and inspiration for human therapeutics, ${ }^{1}$ providing novel molecular scaffolds and biological activities. In the pos genomic era, information concerning the biosynthesis of secondary metabolite has been gained together with the observation that the number of genes encoding biosynthetic enzymes in fungi outnumbers the known secondary metabolites synthesized by these microorganisms, indicating that only a subset of biosynthetic pathway genes is expressed under standard laboratory culture conditions. ${ }^{2}$ Efforts of trying to unlock these cryptic secondary metabolites have been made worldwide and in many cases successfully accessed using molecular and cultivation-based approaches. ${ }^{3}$ One topdown methodology is the one strain-many compounds (OSMAC) approach in which by systematically modifying

*e-mail: taicia@iqm.unicamp.br the fermentation parameters, some of these unknown compounds were able to be induced leading to the discovery of new fungal natural products. ${ }^{3,4}$

Penicillium brasilianum LaBioMMi 136, isolated as endophyte from the root bark of Melia azedarach, has been demonstrated to be an important producer of bioactive secondary metabolites, mainly brasiliamides, ${ }^{5}$ austin-related insecticidal meroterpenes, ${ }^{6-8}$ verruculogenlike tremorgenic alkaloids ${ }^{9}$ and spirohexalines, which are new inhibitors of bacterial undecaprenyl pyrophosphate synthase. ${ }^{10}$ In our continuous studies concerning the chemistry and biochemistry of this microorganism, no cyclodepsipeptides have been described for this Penicillium species so far.

In this study, we aim to unlock cryptic secondary metabolites in P. brasilianum LaBioMMi 136 based on the OSMAC approach. The modification of culture medium composition led to the induction of a secondary metabolite identified as the cyclodepsipeptide JBIR 1131 described for the first time in this species which was co-produced to JBIR 
114 and JBIR 115 identified by liquid chromatography tandem mass spectrometry (LC-MS/MS) fragmentation pattern. Details of the isolation, structural elucidation, and biological assays of JBIR 113 are presented herein.

\section{Experimental}

Microorganism

P. brasilianum LaBioMMi 136 used in the present work is deposited at the Laboratório de Bioquímica Micromolecular de Microorganismos (LaBioMMi) of the Departamento de Química, Universidade Federal de São Carlos, São Carlos, Brazil.

\section{General experimental procedures}

${ }^{1} \mathrm{H}$ NMR, ${ }^{13} \mathrm{C}$ NMR and 2D experiments: gradientselected heteronuclear single quantum coherence (gHSQC $\left.\left({ }^{1} \mathrm{H} /{ }^{1} \mathrm{H}\right)\right)$ and gradient-selected heteronuclear multiple bond coherence $\left(\mathrm{gHMBC}\left({ }^{1} \mathrm{H} /{ }^{13} \mathrm{C}\right)\right)$, were recorded in $\mathrm{CHCl}_{3}-d$ (Aldrich) on Bruker Avance III spectrometer operating at $600 \mathrm{MHz}$ and TMS was used as internal standard. Mass spectra (electrospray ionization) were measured in a Waters QuattroLC spectrometer. High performance liquid chromatography (HPLC) separations were performed on a reversed-phase analytical Luna C18 $(4.6 \times 250 \mathrm{~mm}$, $5 \mu \mathrm{m})$ using a Waters HPLC equipped with a photodiode array (PDA). High resolution mass spectrometry (HRMS) analyses were obtained on a Thermo Scientific LTQ Orbitrap Velos Thermo with an electrospray ionization (ESI) ion source. Preparative reversed-phase HPLC purifications were performed on a Luna C18 preparative column $(21.2 \times 250 \mathrm{~mm}, 10 \mu \mathrm{m})$ in a Shimadzu SIL-20AP VP equipped with a Communication BUS Module CMB-20A, LC20AP gradient pumps, SPD-20AV UV detector, DGU-20A degasser and LC SOLUTION software. Matrix-assisted laser desorption ionization time-of-flight (MALDI-TOF) analysis was performed on AutoFlex Speed (Bruker Daltonics) controlled by FlexControl 3.3 software.

\section{Fermentation and purification of compound 1}

The fungus $P$. brasilianum was submitted to two different cultivation conditions and evaluated concerning metabolite production. In the first condition, the fungus was grown statically at room temperature in $250 \mathrm{~mL}$ Erlenmeyer flasks containing $50 \mathrm{~mL}$ of Czapeck liquid medium composed of glucose $\left(26.7 \mathrm{~g} \mathrm{~L}^{-1}\right), \mathrm{NaNO}_{3}$ (3.0 g L L $\left.{ }^{-1}\right), \mathrm{K}_{2} \mathrm{HPO}_{4}\left(1.0 \mathrm{~g} \mathrm{~L}^{-1}\right), \mathrm{MgSO}_{4} \cdot 7 \mathrm{H}_{2} \mathrm{O}\left(0.5 \mathrm{~g} \mathrm{~L}^{-1}\right)$, $\mathrm{KCl}\left(0.5 \mathrm{~g} \mathrm{~L}^{-1}\right), \mathrm{FeSO}_{4} \cdot 7 \mathrm{H}_{2} \mathrm{O}\left(0.01 \mathrm{~g} \mathrm{~L}^{-1}\right)$. The second condition evaluated was based on the supplementation of the described Czapeck medium with $\mathrm{CaCl}_{2}, \mathrm{CuSO}_{4}$, glycerol, $\mathrm{KCl}, \mathrm{MnSO}_{4}$ in a final concentration of $0.5 \mathrm{~g} \mathrm{~L}^{-1}$. After 15 days fermentation, the mycelium was separated by filtration and metabolite extraction was done twice with $30 \mathrm{~mL}$ of ethyl acetate. The mycelium was further extracted with ethanol $(150 \mathrm{~mL})$ to yield an ethanolic crude extract. The combined organic phases (ethyl acetate) obtained were dried with $\mathrm{Na}_{2} \mathrm{SO}_{4}$, and the solvent was removed under reduced pressure producing a yellowish residue, which was subjected to low-pressure silica gel CC eluted with a hexane to methanol gradient (hexane 100\%, hexane:ethyl acetate 90:10, hexane:ethyl acetate 50:50, hexane:ethyl acetate:methanol 45:45:10, methanol 100\%). The fraction eluted with hexane:ethyl acetate:methanol 45:45:10 was reiteratively chromatographed in preparative reversed-phase high performance liquid chromatography (RP-HPLC) using the following gradient: 0-15 min, 30\% MeOH; 15-30 min, $70 \% \mathrm{MeOH} ; 30-40$ min, $90 \% \mathrm{MeOH}$; 40-50 min, 100\% $\mathrm{MeOH}$; and the compound $\mathbf{1}$ at 27.5 minutes was obtained pure $(1.5 \mathrm{mg})$ for further characterization. The mobile phase flow rate was $0.7 \mathrm{~mL} \mathrm{~min}^{-1}$.

\section{Parasites and cells}

Leishmania amazonensis promastigote forms (MHOM/BR/Josefa) were maintained at $25^{\circ} \mathrm{C}$ in Warren's medium (brain heart infusion plus haemin and folic acid) $\mathrm{pH} 7.0$, supplemented with $10 \%$ fetal bovine serum (FBS, Gibco Invitrogen, Grand Island, NY, USA). Epimastigote forms of Trypanossoma cruzi (Y strain) were maintained at $28^{\circ} \mathrm{C}$ in liver infusion tryptose medium (LIT) supplemented with 10\% inactivated FBS and trypomastigote forms were obtained from the supernatant of a monolayer of infected $\mathrm{LLCMK}_{2}$ cells (epithelial cells from the kidney of the monkey Macaca mulatta) in Dulbecco's modified Eagle's medium (DMEM) supplemented with $10 \%$ FBS at $37{ }^{\circ} \mathrm{C}$ in a humidified $5 \% \mathrm{CO}_{2}$ atmosphere. J774A1 murine macrophages were maintained in tissue flasks with RPMI 1640 medium (Gibco Invitrogen Corporation, New York, USA) pH 7.6, with sodium bicarbonate and L-glutamine added, and supplemented with $10 \% \mathrm{FBS}$ at $37^{\circ} \mathrm{C}$ in a $5 \%$ $\mathrm{CO}_{2}$-air mixture.

\section{Antiproliferative assay}

The effect of the cyclodepsipeptide JBIR 113 was evaluated in promastigotes of L. amazonensis and

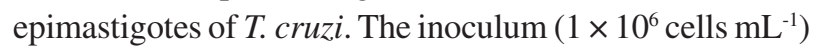
was introduced into 24-well plate containing the compounds dissolved in dimethyl sulfoxide (DMSO) and Warren's 
medium or LIT in several concentrations $(1.0-100.0 \mu \mathrm{M})$. The final concentration of DMSO did not exceed $1 \%$. Cell growth was determined by counting the parasites with a Neubauer hemocytometer after incubation for $72 \mathrm{~h}$ at $25^{\circ} \mathrm{C}$ for $L$. amazonensis or for $96 \mathrm{~h}$ at $28{ }^{\circ} \mathrm{C}$ for $T$. cruzi. The results were expressed as percentage of inhibition in relation to the control cultured. The 50\% inhibitory concentration $\left(\mathrm{IC}_{50}\right)$ was determined by logarithm regression analysis of the data obtained.

\section{Viability of trypomastigote forms of T. cruzi}

The tissue-culture-derived trypomastigote forms $\left(1 \times 10^{7}\right.$ cells $\left.\mathrm{mL}^{-1}\right)$ were resuspended in DMEM and added in duplicate to 96-well microplates in presence of different concentrations of the compounds $(1.0-100.0 \mu \mathrm{M})$. Parasites were incubated for $24 \mathrm{~h}$ at $37^{\circ} \mathrm{C}$ in a $5 \% \mathrm{CO}_{2}$ atmosphere. The results were obtained by observing motility, allowing the determination of the viability of the parasites, using the Pizzi-Brener method. ${ }^{11}$ The $\mathrm{EC}_{50}$ value (i.e., the concentration that lyses $50 \%$ of the parasites) was then calculated.

\section{Antimicrobial assays}

Antibacterial activity was determined essentially as described elsewhere ${ }^{12}$ following the microbroth dilution assay as recommended by Clinical and Laboratory Standards Institute (2006) (former NCCLS). Antimicrobial activity was evaluated against Staphylococcus aureus (ATCC 25923), Escherichia coli (ATCC 25922) and Pseudomonas aeruginona (ATCC 27853) which had the identity confirmed by MALDI-TOF analysis. The assays were performed on 96-well plates, in triplicate in the concentrations of $100,50,25,12.5,6.25$ and $3.121 \mu \mathrm{g} \mathrm{mL}^{-1}$ dissolved in $5 \% \mathrm{DMSO}$. The tested bacteria were incubated in the Mueller Hinton (MH) broth for $18 \mathrm{~h}$ at $37^{\circ} \mathrm{C}$, and the bacteria concentration was diluted to approximately $2.5 \times 10^{6} \mathrm{CFU}$ with $\mathrm{MH}$ broth. In each well were added MH broth $(75 \mu \mathrm{L})$, test compound $(5 \mu \mathrm{L})$ and test bacteria

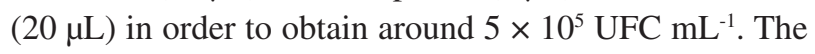
plates were incubated at $37{ }^{\circ} \mathrm{C}$ overnight. Bioactivity was recorded by the use of resazurin dye as blue coloration in the wells. Tetracycline was used as a positive control and pure DMSO was the negative control.

\section{Results and Discussion}

One strain-many compounds (OSMAC) approach is an useful method to gain access to cryptic secondary metabolites in one single strain by manipulating cultivation conditions. ${ }^{4}$ There are extensive examples in which OSMAC approach has been successfully applied to produce new secondary metabolites from single fungal strains. ${ }^{4}$ Culture medium composition is one of the key factors that impact on metabolite production of a microorganism. ${ }^{4,13}$ In this sense, the supplementation of different substances in the growth media was evaluated concerning metabolite production by the fungus $P$. brasilianum LaBioMMi 136, with the aim to induce new fungal metabolites coded on its genome but not expressed under standard Czapeck cultivation conditions.

P. brasilianum has been demonstrated to be an important source for natural products. Among these metabolites, we previously described the production and characterization of the tremorgenic mycotoxins verruculogen 2 , verruculogen TR-2 and a C-11 epimer of verruculogen TR-2. ${ }^{9}$ Following the OSMAC approach, our strain P. brasilianum LaBioMMi 136 has been submitted to different cultivation conditions and the addition of $\mathrm{CaCl}_{2}, \mathrm{CuSO}_{4}$, glycerol, $\mathrm{KCl}, \mathrm{MnSO}_{4}$ was evaluated concerning the metabolic profile. The substances $\mathrm{CaCl}_{2}$, glycerol and $\mathrm{KCl}$ showed no impact on the metabolism of $P$. brasilianum, resulting in the same chromatographic pattern when analyzed by LC-MS compared to standard condition of growth (data not shown). On the other hand, the analysis of the ethanolic fraction obtained by mycelium extraction, indicated that the addition of $\mathrm{CuSO}_{4}$ led to completely inhibition of verruculogen 2 biosynthesis by the fungus using the new cultivation conditions as indicated in the chromatogram shown in Figure 1. $\mathrm{MnSO}_{4}$ also had an important influence on $P$. brasilianum secondary metabolism and the decrease on verruculogen 2 production was observed.

In addition to the lack of the fungus's ability to synthesize verruculogen 2 in the medium supplemented with $\mathrm{CuSO}_{4}$ and $\mathrm{MnSO}_{4}, P$. brasilianum was able to induce a new compound under these conditions which was detected by HPLC-MS in the ethyl acetate fraction and was not observed under standard Czapeck cultivation conditions as indicated in the control experiment shown in Figure 2. The induced compound was isolated by the use of combined chromatographic procedures and identified by physical methods, mainly 1D and 2D NMR experiments and HRMS analysis.

Compound 1 was obtained as a colorless amorphous solid and it was assigned the molecular formula $\mathrm{C}_{31} \mathrm{H}_{42} \mathrm{~N}_{5} \mathrm{O}_{7}$ via HRESIMS data $\left(\mathrm{m} / \mathrm{z}\right.$ for $\left.596.3051[\mathrm{M}+\mathrm{H}]^{+}\right)$, establishing an index of hydrogen deficiency (IHD) of $13 .{ }^{1} \mathrm{H}$ NMR (Table 1) revealed the presence of five $\alpha$ protons at $\delta_{\mathrm{H}} 4.70$, 4.47, 4.57, 4.26 and 4.92 for $\mathrm{H}-2, \mathrm{H}-8, \mathrm{H}-14, \mathrm{H}-19$ and $\mathrm{H}-22$, respectively. Moreover, two $\mathrm{NH}$ protons at $\delta_{\mathrm{H}} 7.17$ and 7.20 were observed. ${ }^{13} \mathrm{C}$ NMR pointed six carbonyl carbons at 


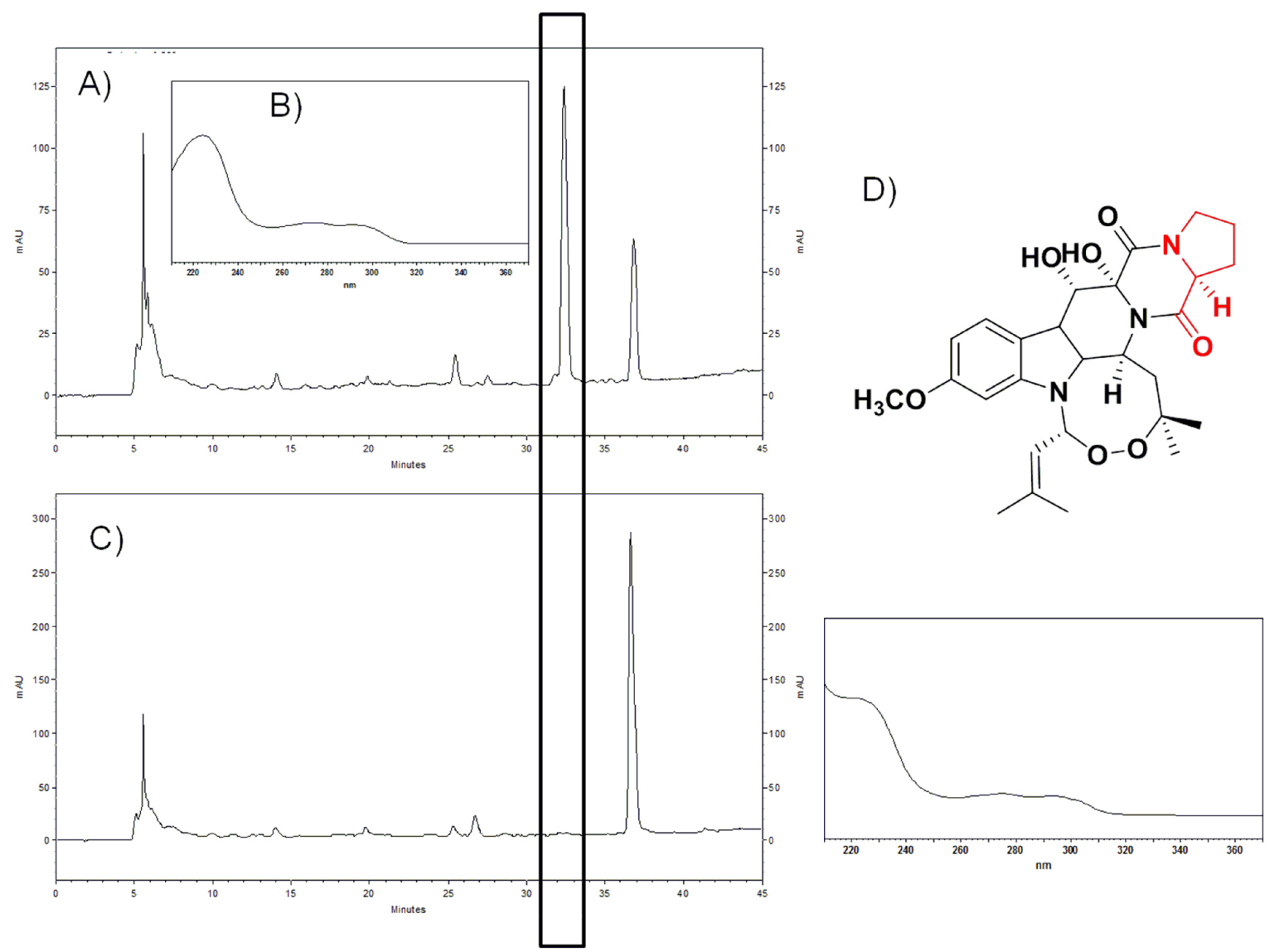

Figure 1. (A) Metabolic profile of $P$. brasilianum LaBioMMi 136 cultivated in Czapeck standard medium; (B) UV spectrum of 2 produced by the fungus in standard conditions; (C) metabolic profile of $P$. brasilianum LaBioMMi 136 under the influence of $\mathrm{CuSO}_{4}$ added in the medium, indicating verruculogen $\mathbf{2}$ biosynthesis abolished; (D) chemical structure of $\mathbf{2}$ and the UV spectrum of $\mathbf{2}$ standard, respectively.

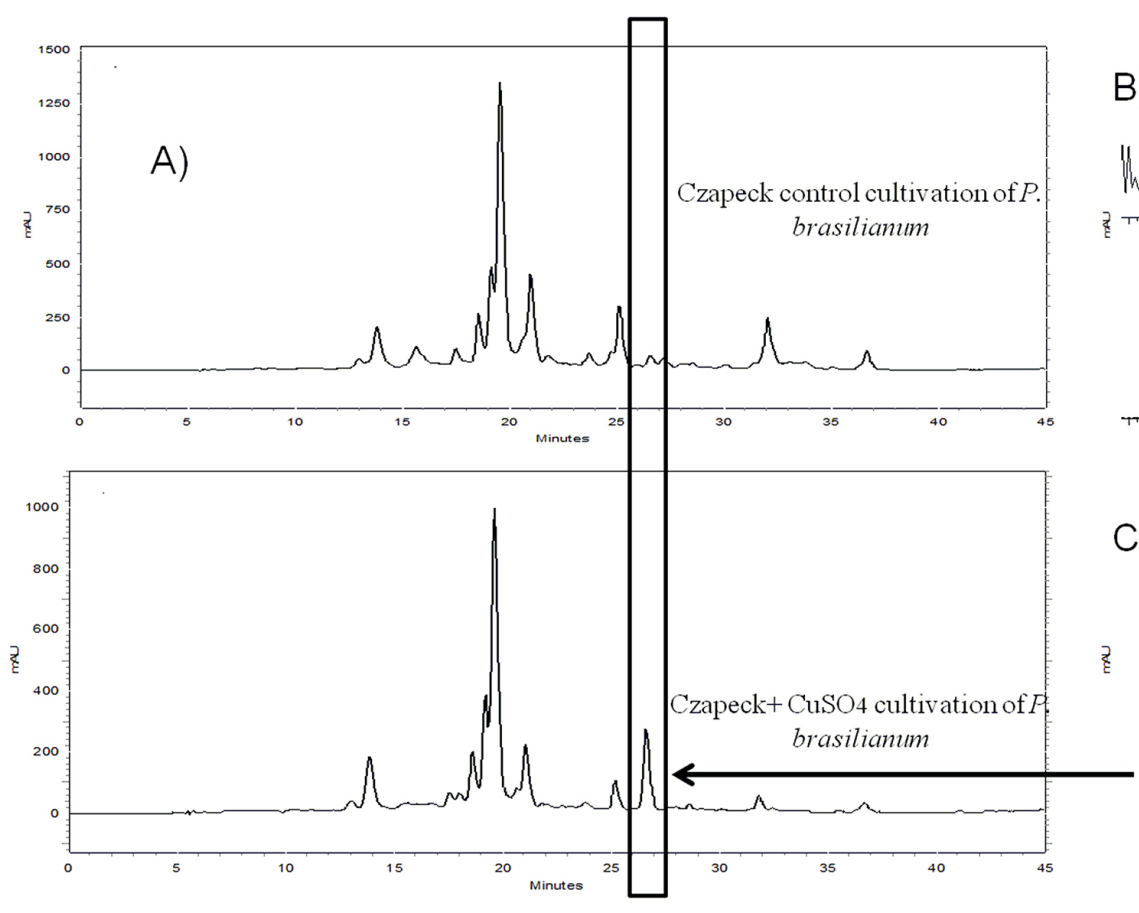

B) Control

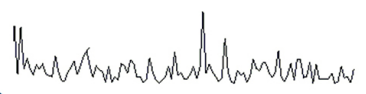

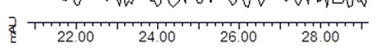

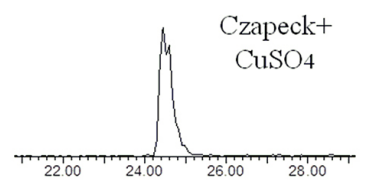

C)

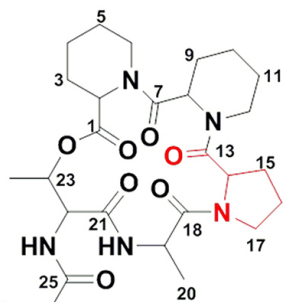

31

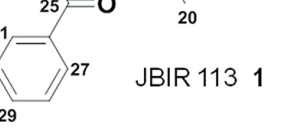

Molecular Weight: 595.70

Figure 2. (A) Metabolic profile of $P$. brasilianum LaBioMMi 136 cultivated in standard cultivation conditions and under the influence of CuSO ${ }_{4}$, respectively; (B) selected ion chromatogram of $m / z, 596$ of control and $\mathrm{CuSO}_{4}$ culture, respectively; (C) chemical structure of the cyclodepsipeptide JBIR 1131 induced. 
$\delta_{\mathrm{C}} 174.3,169.3,173.4,172.4,169.0$ and 167.6 related to C-1, C-7, C-13, C-18, C-21 and C-25, respectively. These spectral features collectively suggested the peptide nature of the molecule. Correlation spectrometry (COSY) and HMBC were the key in the establishment of spin systems (Figure 3), leading to the identification of a threonine (Thr) moiety (from $\mathrm{NH}$ at $\delta 7.20$ to $\mathrm{H}-22$ and $\mathrm{H}-23$ and from $\mathrm{H}-23$ to $\mathrm{H}-24$ ), an alanine (Ala) moiety (from $\mathrm{NH}$ at $\delta 7.17$ to $\mathrm{H}-19$ and from $\mathrm{H}-19$ to $\mathrm{H}-20$ ), a proline (Pro) moiety (from $\alpha$ protons at $\delta 4.57$ to $\mathrm{H}-15 \mathrm{a} / \mathrm{b}$ and from methylene proton at $\delta 1.70$ to $\mathrm{H}-17 \mathrm{a}$ ), and two pipecolic acid (Pip) residues

Table 1. NMR data of compound $1\left(600 \mathrm{MHz}, \mathrm{CDCl}_{3}\right)$

\begin{tabular}{|c|c|c|c|}
\hline Unit & Position & $\delta_{\mathrm{H}}, \mathrm{m}(J$ in $\mathrm{Hz})$ & $\delta_{\mathrm{c}}$ \\
\hline \multirow[t]{8}{*}{ Pip 1} & 1 & - & 169.0 \\
\hline & 2 & 4.47 & 53.5 \\
\hline & $3 a$ & $1.87, \mathrm{ovl}^{\mathrm{a}}$ & 27.3 \\
\hline & $3 b$ & $1.93, \mathrm{ovl}^{\mathrm{a}}$ & \\
\hline & 4 & $1.65, \mathrm{ovl}^{\mathrm{a}}$ & 18.5 \\
\hline & $5 \mathrm{a}$ & $1.40, \mathrm{ovl}^{\mathrm{a}}$ & 23.9 \\
\hline & $5 \mathrm{~b}$ & $1.82, \mathrm{ovl}^{\mathrm{a}}$ & \\
\hline & 6 & $3.32, \mathrm{ovl}^{\mathrm{a}}$ & 39.1 \\
\hline \multirow[t]{9}{*}{ Pip 2} & 7 & - & 174.3 \\
\hline & 8 & $4.70, \mathrm{dl}(4.1)$ & 50.9 \\
\hline & $9 \mathrm{a}$ & 1.84, ovl $^{\mathrm{a}}$ & 26.2 \\
\hline & $9 b$ & 1.99, ovl $^{\mathrm{a}}$ & \\
\hline & 10 & $1.75-1.65, \mathrm{~m}$ & 18.8 \\
\hline & $11 \mathrm{a}$ & $1.70, \mathrm{ovl}^{\mathrm{a}}$ & 24.0 \\
\hline & $11 \mathrm{~b}$ & 1.83, ovl $^{\mathrm{a}}$ & \\
\hline & $12 \mathrm{a}$ & 3.70, ovl $^{\mathrm{a}}$ & 43.5 \\
\hline & $12 \mathrm{~b}$ & - & \\
\hline \multirow[t]{8}{*}{ Pro } & 13 & - & 173.4 \\
\hline & 14 & $4.57, \mathrm{ovl}^{\mathrm{a}}$ & 59.1 \\
\hline & $15 \mathrm{a}$ & $2.09, \mathrm{ovl}^{\mathrm{a}}$ & 30.0 \\
\hline & $15 b$ & $2.41, \mathrm{ovl}^{\mathrm{a}}$ & \\
\hline & $16 \mathrm{a}$ & 1.84, ovl $^{\mathrm{a}}$ & 24.0 \\
\hline & $16 \mathrm{~b}$ & $1.70, \mathrm{ovl}^{\mathrm{a}}$ & \\
\hline & $17 \mathrm{a}$ & $3.67, \mathrm{ovl}^{\mathrm{a}}$ & 47.4 \\
\hline & $17 \mathrm{~b}$ & 3.58, ovl $^{\mathrm{a}}$ & \\
\hline \multirow[t]{4}{*}{ Ala } & 18 & - & 172.4 \\
\hline & 19 & $4.26-4.24, \mathrm{~m}$ & 47.45 \\
\hline & 20 & 1.27, d (3.6) & 19.7 \\
\hline & NH & 7.21-7.17, m & - \\
\hline \multirow[t]{5}{*}{ Thr } & 21 & - & 168.0 \\
\hline & 22 & $4.92, \mathrm{~d}(8.2)$ & 55.7 \\
\hline & 23 & $5.29, \mathrm{q}(6.2)$ & 73.3 \\
\hline & 24 & $1.34, \mathrm{~d}(5.8)$ & 17.1 \\
\hline & $\mathrm{NH}$ & 7.21-7.17, m & - \\
\hline \multirow[t]{5}{*}{$\mathrm{Bz}$} & 25 & - & 167.7 \\
\hline & 26 & - & 134.1 \\
\hline & 27 & 7.84, d (7.4) & 127.3 \\
\hline & 28 & $7.47, \mathrm{t}(7.4)$ & 128.5 \\
\hline & 29 & $7.53, \mathrm{t}(7.4)$ & 131.7 \\
\hline
\end{tabular}

${ }^{a}$ Overlapped with other signals. (from $\alpha$ protons at $\delta 4.47$ and 4.70 to $\mathrm{C}-3, \mathrm{C}-4$ and $\mathrm{C} 5$, and C-9, C10, C-12, respectively).

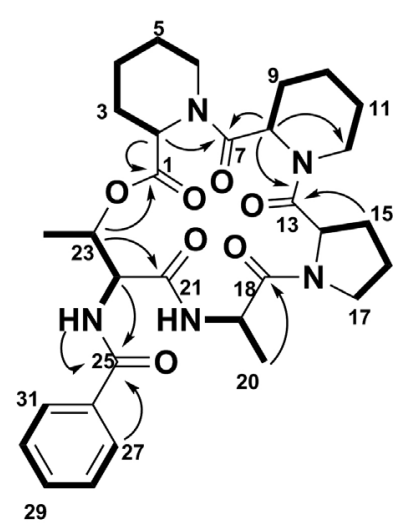

Figure 3. Key correlations COSY (bold lines) and HMBC (arrows) of compound 1.

Furthermore, the ${ }^{1} \mathrm{H}$ NMR and COSY spectra revealed the presence of aromatic hydrogens H-27/31, H-28/30 and H-29. COSY correlations from $\mathrm{H}-27 / 31$ (7.84, $\mathrm{d}, 7.4)$ to $\mathrm{H}-28 / 30$ (7.47, t, 7.4) and $\mathrm{H}-28 / 30$ to $\mathrm{H}-29$ (7.53, t, 7.4) and HMBC correlations from H-28 $\leftrightarrow$ C-26 (134.1) and from $\mathrm{H}-27 / 31 \leftrightarrow \mathrm{C}-25$ (167.7), indicating a benzoyl group. Correlations of $\alpha$ and $\mathrm{NH}$ protons to each carbonyl carbons supported to establish the connectivities of the amino acids and the benzoyl unit. HMBC correlations from H-2 at $\delta_{\mathrm{H}} 4.47, \alpha$ methine hydrogen of Pip 1, to a carbonyl carbon of Pip 2 at $\delta_{\mathrm{C}} 174.3$, from $\alpha$ methine hydrogen of Pip 2 at $\delta_{\mathrm{H}} 4.70$ to carbonyl carbon of Pro at $\delta_{\mathrm{C}} 173.4$, from $\beta$-methylene hydrogen $\mathrm{H}-15 \mathrm{a}$ at $\delta_{\mathrm{H}} 2.09$ to carbonyl carbon of Pro and to carbonyl carbon of Ala at $\delta_{\mathrm{C}} 172.4$, from an $\alpha$-methine hydrogen Ala $\mathrm{H}-19$ at $\delta_{\mathrm{H}} 4.25$ to a carbonyl carbon of Thr C-21 at $\delta_{\mathrm{C}} 168.0$, from an amide hydrogen of Thr -NH at $\delta_{\mathrm{H}} 7.20$ to a carbonyl carbon of Bz C-25 at $\delta_{\mathrm{C}}$ 167.6. Furthermore, the correlation from the oxymethine hydrogen of Thr H-23 at $\delta_{\mathrm{H}} 5.29$ to a carbonyl carbon of Pip $1 \mathrm{C}-1$ at $\delta_{\mathrm{C}} 169.3$ represents the connection between them and shows an ester bond, indicating the chemical structure of a depsipeptide.

Fragmentation studies were performed in order to establish the correct connectivity between amino acids in the cyclodepsipeptide JBIR 113. The MS data were acquired in positive ion mode to produce the molecular ion $[\mathrm{M}+\mathrm{H}]^{+}$at $\mathrm{m} / \mathrm{z}, 596$ by protonation of the nitrogen atom in the peptide bond involved in the correspondent ring opening, according to our theoretical fragmentation proposal. The product ion spectra of compound 1 showed $\mathrm{m} / \mathrm{z}, 485,467,374,356,280,209,140,112$ and 70 as the most abundant product ions, being the result of the two most important ring openings 1 and 2 as assigned in the structure of compound 1 (Figure 4). 
Ring open 1

(B)

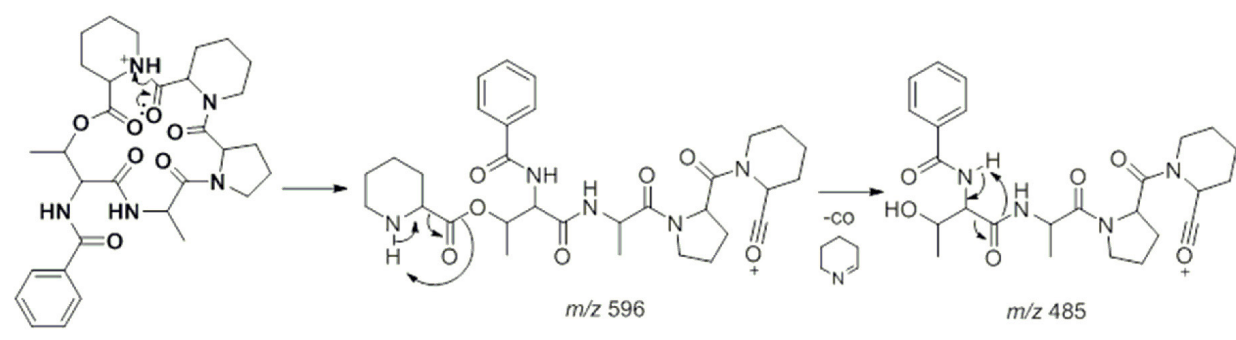
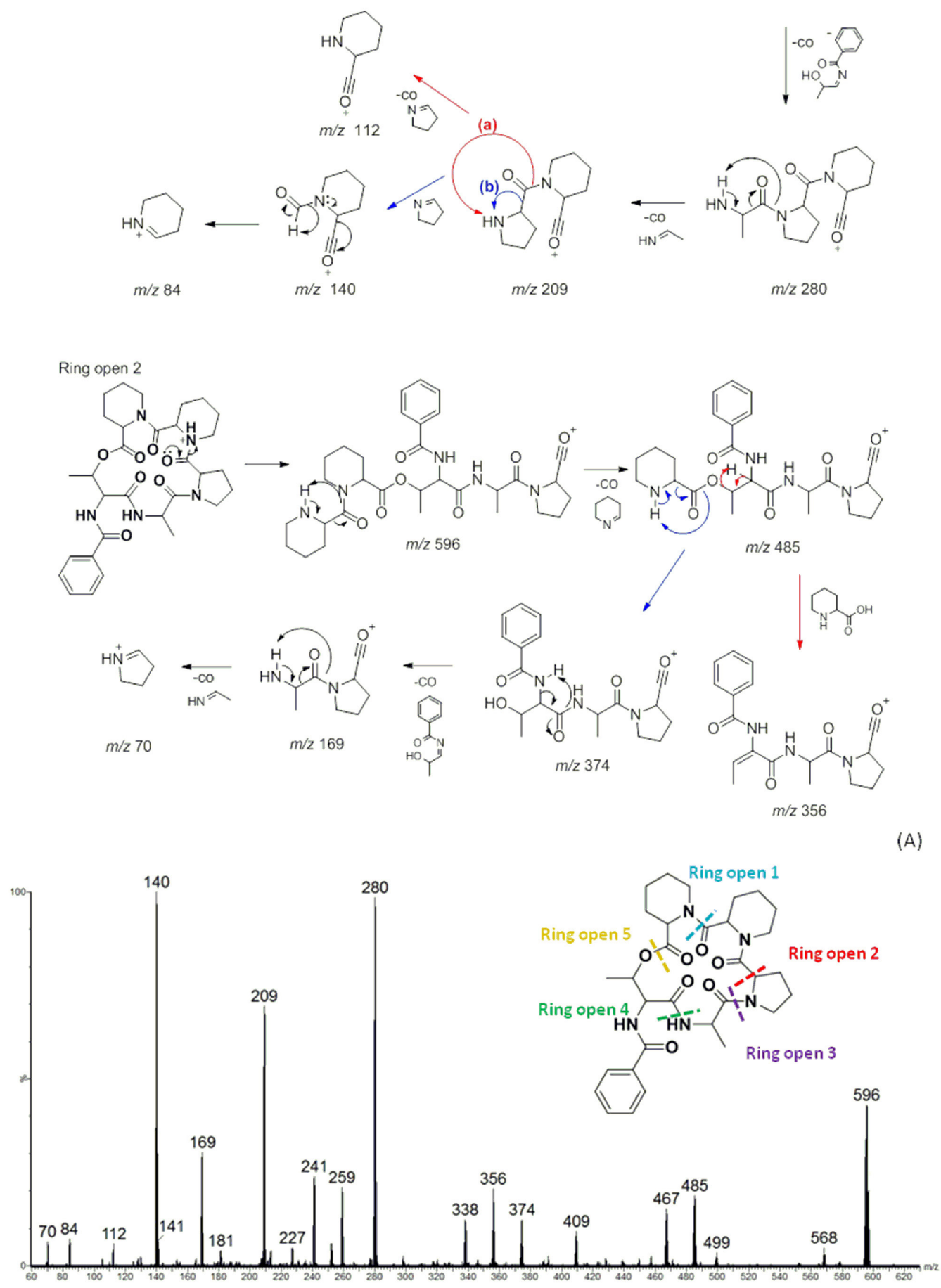

Figure 4. (A) Product ion of [M+H] $]^{+}$at $m / z 596$ and possibilities of ring opening; (B) fragmentation proposal for compound 1. 


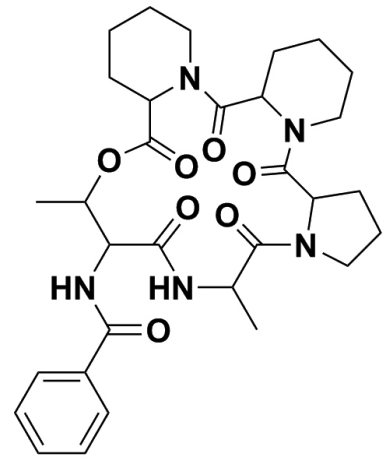

JBIR113

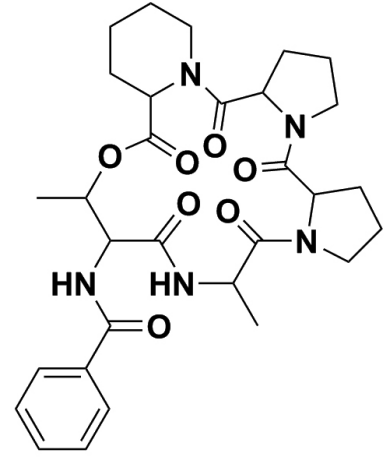

JBIR114

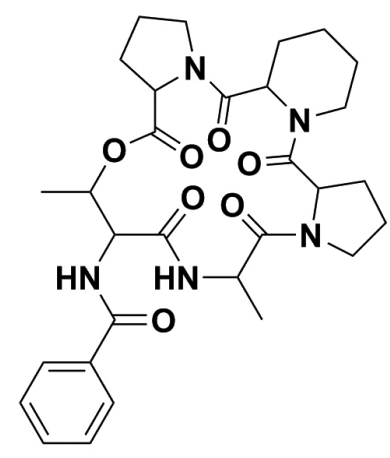

JBIR115

Figure 5. Chemical structures of the cyclodepsipeptides JBIR 113, JBIR 114 and JBIR 115 produced by P. brasilianum.

The proposal is based on the ring opening mechanisms followed by a sequence of $1,3 \mathrm{H}$ shifts as indicated in the proposal. The first $\mathrm{H}$ shift proceeds with $\mathrm{CO}$ and $\mathrm{C}_{5} \mathrm{H}_{7} \mathrm{~N}$ losses leading to the ions $m / z 485$ (ring opening 1) and $\mathrm{m} / \mathrm{z}, 485$ (ring opening 2) which further go through a new $1,3 \mathrm{H}$ shift in two different positions as indicated in Figure 4, leading to $m / z, 280$ (ring opening 1 ) and $m / z 374$ and 356 (ring opening 2). Finally one last $1,3 \mathrm{H}$ shift is responsible for the formation of the further ions. Based on the product ions and fragmentation proposal, we were able to assign the correct positions of the amino acids in the structure of compound $\mathbf{1}$. The cyclodepsipeptides JBIR 114 and JBIR 115 (Figure 5) were co-produced to JBIR 113 by the fungus $P$. brasilianum as indicated by LC-MS/ MS analyses with similar peptide fragmentation pattern (Supplementary Information, Figure S7).

MS/MS data of JBIR 114 indicated characteristic loss of one Pip ( $\mathrm{m} / \mathrm{z} 493)$ and two Pro $(\mathrm{m} / \mathrm{z} 396$ and 299), respectively. On the other hand, MS/MS pattern of JBIR 115 indicated loss of a Pro $(\mathrm{m} / \mathrm{z}, 489)$ which allowed distinguishing both isomers due to the loss of a proline unit (Supplementary Information, Figure S7). A few other cyclodepsipeptides were induced by the culture conditions and are currently under investigation in our laboratory.

Compound 1 was identified as the cyclodepsipeptide JBIR 113 already described by Kawahara et al. ${ }^{14}$ which was produced by a marine sponge-derived Penicillium sp. fS36 isolated in Japan and was co-produced to other two cyclodepsipeptides JBIR 114 and JBIR 115 that differentiates in the composition and sequence of the amino-acid residues ${ }^{13}$ (Figure 5). This cyclodepsipeptides are structurally related to petrosifungins which are novel cyclodepsipeptides from Penicillium brevicompactum derived from a specimen of the Mediterranean sponge Petrosia ficiformis. ${ }^{15}$ Petrosifungins A and B are cyclodepsipeptides containing two neighboring units of the nonproteinogenic amino acid L-pipecolinic acid as in JBIR 113 produced by P. brasilianum. A noteworthy structural feature of the petrosifungins and JBIR 113 structures is the array of the three neighboring cyclic amino acids proline and twice pipecolinic acid, which are the only examples of this sequence in natural cyclopeptides. ${ }^{15}$ Although other peptides containing pipecolic acid have been reported, including neamphamide $\mathrm{A}^{16}$ from a marine sponge and microsporins $\mathrm{A}$ and $\mathrm{B}^{17}$ from a marine spongederived fungus, these peptides are very rare in natural products and are all of marine origin and it is the first time described by a terrestrial microorganism.

Compound 1 isolated from P. brasilianum was submitted to biological assays and evaluated against promastigote forms of L. amazonensis and epimastigote and trypomastigote forms of T. cruzi. The compound $\mathbf{1}$ was found inactive in the bioassays exhibiting an $\mathrm{IC}_{50}$ value (inhibitory concentration for $50 \%$ of the parasites) of $63.2 \pm 2.5 \mu \mathrm{M}$. Compound $\mathbf{1}$ was found to be inactive concerning antimicrobial activity against Pseudomonas aeruginosa, Staphylococcus aureus or Escherichia coli. Although the negative result was given, further studies still need to explore their potential bioactivity.

It is well-established that fumitremorgen-verruculogen metabolites are biochemically derived from tryptophan, proline and one or more mevalonic acid moieties ${ }^{18}$ confirmed by isotopically labeling studies and recent molecular approaches. From our understanding, it seems that the fungus $P$. brasilianum has the ability to redirect the amino acid proline that was once used for verruculogen production to biosynthesize the cyclodepsipeptides JBIR 113, JBIR 114 and JBIR 115 which contains a proline in its chemical structure and is not produced under standard cultivation conditions.

P. brasilianum LaBioMMi 136 recently had its genome sequenced (data not published) and the related information was submitted to prediction tools that find gene clusters and pathways in fungal genomes. AntiSmash ${ }^{19}$ analysis 
indicated that $P$. brasilianum has the potential to produce a diverse array of natural products. According to antiSmash analysis, there are 42 putative biosynthetic gene clusters in P. brasilianum LaBioMMi 136 containing, among others, 22 backbone genes, of which 12 are nonribosomal peptide synthetases (NRPSs); indicating the great genetic and enzymatic machinery potential for the production of peptide related metabolites. Further studies will be performed in order to understand JBIR 113 biosynthetic cluster.

\section{Conclusions}

The future of microbial natural product drug discovery and development remains bright and OSMAC approach is a good strategy to gain access to new natural products from a single fungal strain. The present studies have showed that microorganisms are sensitive to culture media for production of secondary metabolites, and that changing the culture medium could lead to changes in metabolite profiles. By the addition of different salts in the culture medium, P. brasilianum locked the production of verruculogen and at the same time redirect the amino acid proline to produce a series of cyclodepsipeptides never described for this species before and characteristic of marine fungal species, describing the ability of a terrestrial organism to produce cyclodepsipeptides with three neighboring cyclic amino acids proline and twice pipecolinic acid.

\section{Supplementary Information}

Supplementary data (NMR, MS, MS/MS spectra) are available free of charge at http://jbcs.sbq.org.br as PDF file.

\section{Acknowledgments}

The authors are grateful to the Brazilian institutions (Fundação de Amparo à Pesquisa do Estado de São Paulo (FAPESP, Process No. 2014/03510-2 and 2010/52312-8), Conselho Nacional de Desenvolvimento Científico e Tecnológico (CNPq), Coordenação de Aperfeiçoamento de Pessoal de Ensino Superior (CAPES) for the financial support.

\section{References}

1. Luo, Y.; Cobb, R. E.; Zhao, H.; Curr. Opin. Microbiol. 2014, $30,230$.

2. Hertweck, C.; Scherlach, K.; Org. Biomol. Chem. 2009, 7, 1753.

3. Chiang, Y. M.; Lee, K. H.; Sanchez, J. F.; Keller, N., P.; Wang, C. C.; Nat. Prod. Commun. 2009, 4, 1505.

4. Bode, H. B.; Bethe, B.; Höfs, R.; Zeeck, A.; Chembiochem 2002, 3, 619 .

5. Fujita, T.; Makishima, D.; Akiyama, K.; Hayashi, H.; Biosci., Biotechnol., Biochem. 2002, 66, 1697.

6. Fill, T. P.; Pereira, G. K.; Santos, R. M. G.; Rodrigues-Filho, E.; Z. Naturforsch. 2007, 62, 1035.

7. Santos, R. M. G.; Rodrigues-Filho, E.; Phytochemistry 2002, 61, 907.

8. Sallum, W. S. T.; Takahashi, J. A.; Quim. Nova 2010, 33, 1044.

9. Fill, T. P.; Asenha, H. B.; Marques, A. S.; Ferreira, A. G.; Rodrigues-Filho, E.; Nat. Prod. Res. 2013, $27,967$.

10. Inokoshi, J.; Nakamura, Y.; Hongbin, Z.; Uchida, R.; Nonaka, K.; Masuma, R.; Tomoda, H.; J. Antibiot. 2013, 66, 37.

11. Brener, Z.; Rev. Inst. Med. Trop. Sao Paulo 1962, 4, 386.

12. Pfaller, M. A.; Rex, J. H.; Rinaldi, M. G.; Clin. Infect. Dis. 1997, 24, 776 .

13. Zhao, Q.; Wanga, G. Q.; Chen, G. D.; Hu, D.; Li, X. X.; Guo, L. D.; Li, Y.; Yao, X. S.; Gao, H.; Steroids 2015, 102, 101.

14. Kawahara, T.; Takagil, M.; Shin-ya, K.; J. Antibiot. 2012, 65, 147.

15. Bringmann, G.; Lang, G.; Steffens, S.; Schaumann, K.; J. Nat. Prod. 2004, 67, 311.

16. Oku, N.; Gustafson, K. R.; Cartner, L. K.; Wilson, J. A.; Shigematsu, N.; Hess, S.; Pannell, L. K.; Boyd, M. R.; McMahon, J. B.; J. Nat. Prod. 2004, 67, 1407.

17. Gu, W.; Cueto, M.; Jensen, P. R.; Fenical, W.; Silverman, R. B.; Tetrahedron 2007, 63, 6535.

18. Day, J. B.; Mantle, P. G.; Appl. Environ. Microbiol. 1982, 43, 514.

19. Blin, K.; Medema, M. H.; Kazempour, D.; Fischbach, M. A.; Breitling, R.; Takano, E.; Webert, T.; Nucleic Acids Res. 2013, 41. DOI: $10.1093 /$ nar/gkt449.

Submitted: February 11, 2016 Published online: May 25, 2016

FAPESP has sponsored the publication of this article 